Génét. Sél. Evol., 1988, 20 (2), 239-246

Note

\title{
The recent introduction of a $1 / 29$ chromosome translocation in South African Brahman cattle
}

\author{
N.D. NEL, E.J. HARRIS, J.E. WEIERMANS and E.H.H. MEYER \\ Animal and Dairy Science Research Institute, Private Bag X2, Irene, 1675, Republic of South Africa
}

\section{Summary}

A 1/29 chromosome translocation was found in a Brahman bull in artificial insemination service. In the subsequent investigation, it was established that most of the semen produced had been sold to commercial breeders. An extended pedigree showed that the translocation was introduced into South Africa by cattle imported from the USA. The anomaly was absent in a random sample of unrelated Brahman cattle.

Key words : cattle, Brahman, chromosome abnormality, translocation.

\section{Résumé}

L'introduction récente d'une translocation chromosomique 1/29 chez des bovins Brahman d'Afrique du Sud

Une translocation chromosomique $1 / 29$ a été détectée chez un Brahman d'insémination artificielle. Des recherches ultérieures ont établi que sa semence avait été, pour la plus grande part, vendue à des élevages commerciaux. Une recherche généalogique a montré que la translocation avait été introduite en Afrique du Sud à l'occasion d'une importation de bovins en provenance des Etats-Unis d'Amérique. L'anomalie n'a pas été retrouvée dans un échantillon aléatoire de bovins Brahman non apparentés.

Mots clés : bovin, Brahman, anomalie chromosomique, translocation.

\section{Introduction}

During routine cytogenetic screening, a Brahman bull from the Artificial Insemination (AI) Co-operative was found to be a 1/29 heterozygote translocation carrier. At that time, this three year old bull had been in service for approximately 18 months, and 14000 doses of frozen semen had already been sold. The distribution was widespread as the Co-operative is the sole commercial supplier of cattle semen in South Africa. 
In view of the importance of this anomaly in world cattle production (Gustavsson, $1969 \& 1979$; Popescu, 1977), the discovery of this bull in AI service was seen in a very serious light. In conjunction with the Brahman Cattle Breeder's Society of South Africa, it was decided to trace the origin and spread in South African Brahman cattle and to investigate the possible effect of the translocation on fertility and growth.

\section{Materials and methods}

Information supplied by the Breeder's Society and the AI Co-operative was used to locate the progeny produced from the sale of affected semen and to draw up an extended pedigree. As the sire and grandsire had died, it was necessary to screen the progeny of these bulls in order to establish the inheritance of the translocation.

Peripheral blood specimens were taken from 227 possible progeny in 12 commercial herds from different parts of the country. Under extensive ranching conditions it is not always possible to distinguish between calves from different bulls. A further 14 related cattle (three herds) were tested together with a random sample of 190 unrelated Brahman cattle. The latter group was studied in order to investigate the incidence of the translocation in the general population. Giemsa stained metaphase spreads were obtained from whole blood lymphocyte cultures using a method adapted from that of MoORHEAD et al. (1960). In this method, concanavaline A $(0.01 \mathrm{mg} / \mathrm{ml})$ was used instead of phytohaemagglutinin. An R-banding method, based on the techniques used by Popescu et al. (1982) and Di Berardino \& IANnuzzi (1982) was used to identify the chromosome abnormality. In this method the length of $5^{\prime}$-Brdu incorporation was reduced to five hours.

The study of growth required an adequate sample of normal and translocation halfsibs under standardized conditions of age and feeding; sibs were necessary to eliminate a sire effect in the analysis. The animals selected were subjected to an analysis of variance (normal versus translocation half-sibs). A sample of 85 normal and 121 translocation records from one farm was available for analysis. The weaning (205 days) and post weaning indices of 12,18 and 24 months were used in the computation. The index is computed as follows :

Index $(\bar{x})=(A D G / A D G$ of the group $) \times 100$

where $\mathrm{ADG}=$ (mass - birth mass $) /$ age in days

\section{Results}

The Giemsa-stained and R-banded spreads confirmed the presence of a $1 / 29$ chromosome translocation (fig. $1 \mathrm{~A}+\mathrm{B}$ ). The presence of the anomaly was confirmed in 78 offspring and other family members found on 15 farms.

The random sample from the general Brahman population revealed a total absence of any translocation carriers (table 1). 


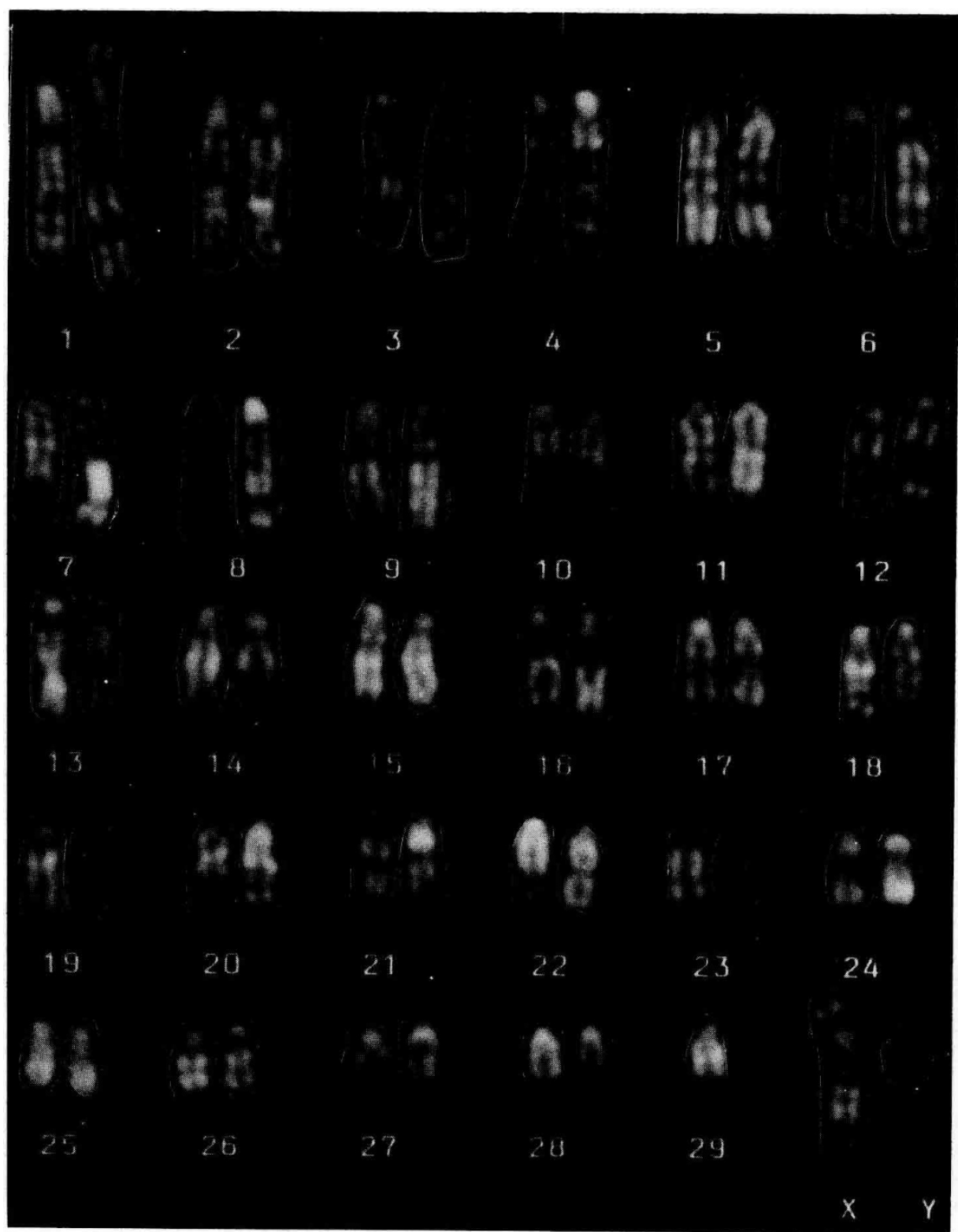

Fig. 1A

The R-banded stained karyotype of the carrier bull. 


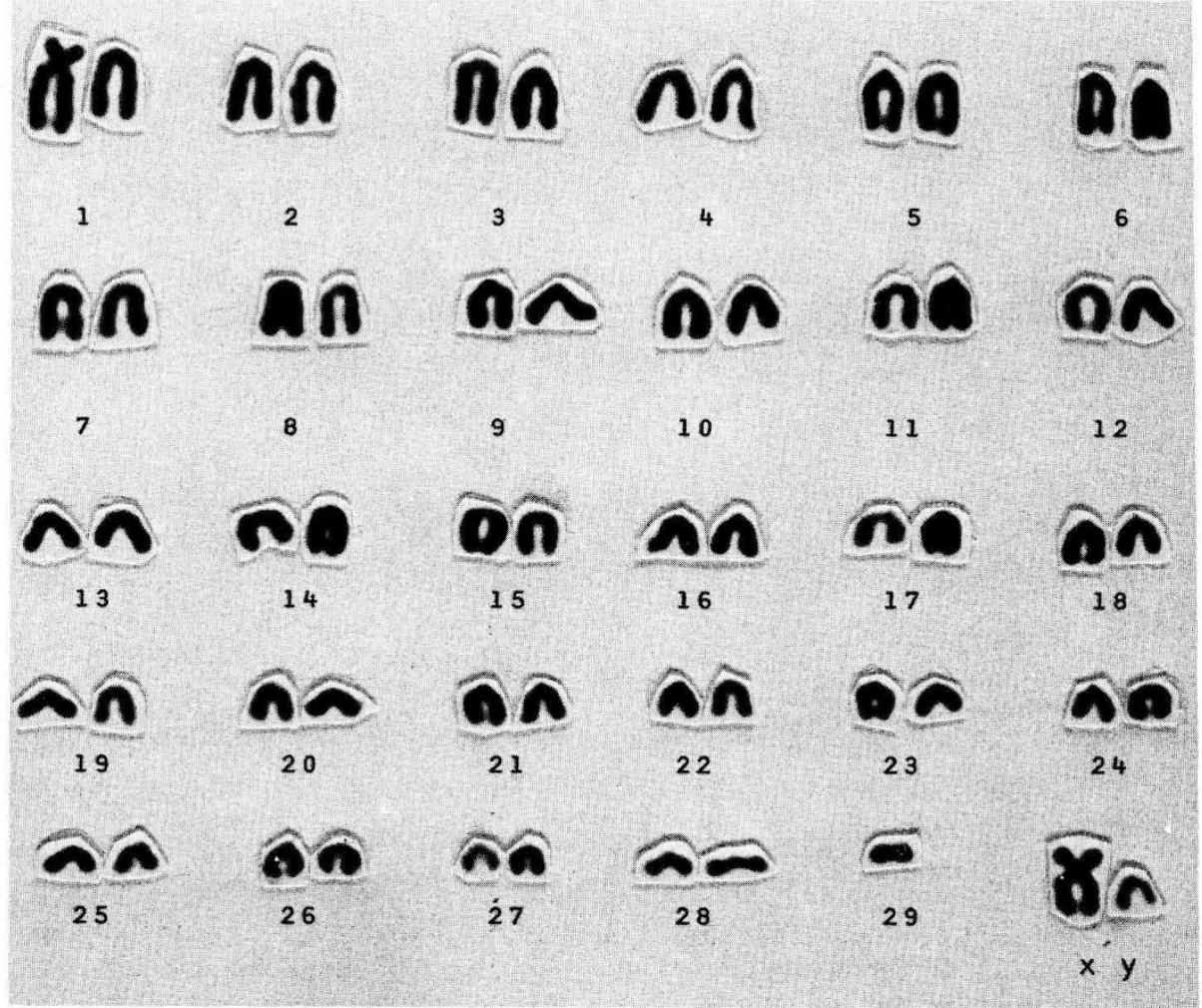

Fig. 1B

The giemsa stained karyotype of a carrier bull (offspring of the bull).

TABLE 1

Translocation carrier cattle in random and affected Brahman herds

\begin{tabular}{l|c|c|c}
\hline \hline & $N^{\circ}$ of herds & Cattle screened & $\begin{array}{c}\mathbf{N}^{\mathrm{o}} \text { of } \\
\text { translocation } \\
\text { carriers }\end{array}$ \\
\cline { 2 - 4 } Affected commercial herds screened & 12 & 227 & 74 \\
Affected stud herds screened & 3 & 14 & 4 \\
General Brahman population & 5 & 190 & 0 \\
\hline \hline
\end{tabular}


The origin of this $1 / 29$ chromosome translocation was tentatively traced to the great-grand dam (4) of the affected AI bull (1) (see fig. 2 for an extended pedigree).
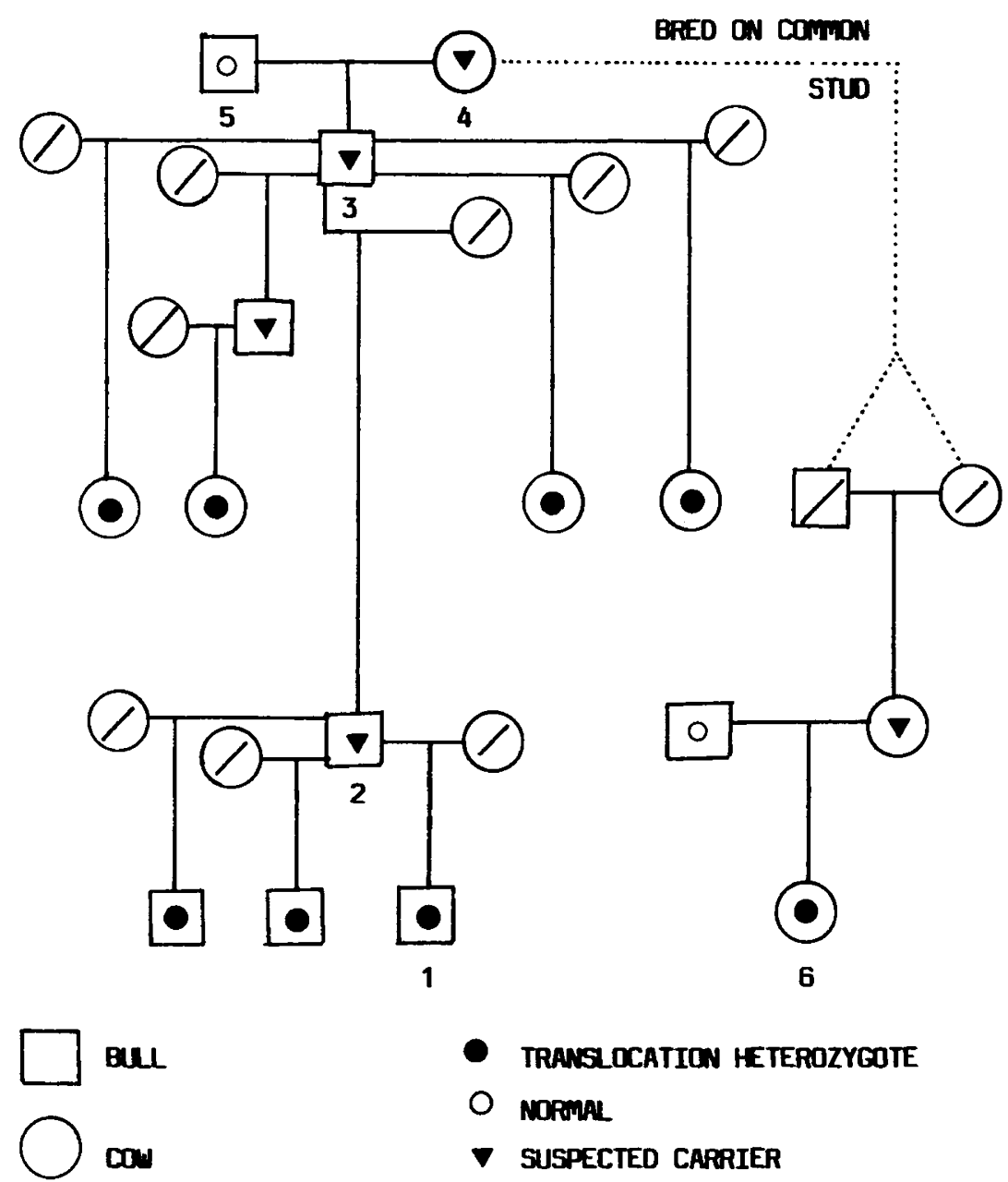

- TRANGLCCATION HETEROZYGOTE

O MONWRL

$\nabla$ SUSPECTED CARRIER

$\checkmark$ MOT aVAILable FOR SCREENIMG

FIG. 2

The extended pedigree of the translocation carrier bull. Only the cattle relevant to this study are shown.

The results of the analysis of variance, comparing the growth rates of normal and translocation sibs, are contained in table 2 . Although the translocation cattle show higher mass indices $(0.5$ to $4.4 \%)$, these differences are not statistically significant $(P<0.05)$. 
TABLE 2

A comparison of growth rates between normal and translocation half-sibs

\begin{tabular}{l|c|c|c|c|c|c}
\hline \multirow{2}{*}{ Age } & \multicolumn{2}{|c|}{ Normal } & \multicolumn{2}{c|}{ Translocation } & $\begin{array}{c}\text { Difference } \\
\left(\bar{x}_{2}-\bar{x}_{1}\right)\end{array}$ & $F$-value \\
\cline { 2 - 7 } & $n$ & $\left(\bar{x}_{1}\right)$ & $n$ & $\left(\bar{x}_{2}\right)$ & & \\
\hline Weaning & & & & & & \\
205 days & 26 & 100.7 & 37 & 101.2 & 0.5 & 0.60 \\
12 months & 24 & 102.3 & 37 & 106.7 & 4.4 & 0.66 \\
18 months & 25 & 101.2 & 35 & 103.8 & 2.6 & 0.83 \\
24 months & 10 & 102.0 & 12 & 105.8 & 3.8 & 0.84 \\
\hline Total & 85 & & 121 & & & \\
\hline \hline
\end{tabular}

\section{Discussion and conclusion}

The large number of chromosomes (relative to humans, pigs and sheep), the morphology of the autosomes and the inconsistent results obtained with banding techniques makes the identification of cattle chromosomes very difficult. Notwithstanding this, the examination of 1600 giemsa stained and 50 R-banded affected metaphase spreads confirms the presence of a fusion between the longest and shortest chromosome ( 1 and 29) in the cattle studied. This is based on the sizes of the fused chromosomes in the case of giemsa staining and on a consistent match between the chromosomes studied and the standard karyotypes published.

A cow (4), thought to be the original carrier, produced four heifers and a bull calf, all of which are dead (fig. 2). Unfortunately, the progeny of these four heifers cannot be located. The translocation was however traced, via his progeny, to the bull calf (3). His sire (5) when screened, was found to be normal. It is thus presumed that the cow (4), the great-grand-dam of the AI bull under investigation, was responsible for the spread of the translocation in this Brahman family.

While conducting this investigation, evidence to support this conclusion came from a seemingly unrelated cow (6), identified as a translocation carrier. The extended pedigree showed that the dam lines from the two translocation families originated from the same stud in the USA. Heifers from this stud were imported in the early 1960's.

The records show that most of the 14000 doses of affected semen have been sold to commercial cattle breeders. This constitutes little if any threat to the Brahman stud industry in South Africa. The bull (1) has subsequently been taken out of AI service. The few animals sold for stud breeding will be traced where possible and reported to the Brahman Breeder's Society.

The identification of translocation carriers was performed with the express purpose of showing to what extent the anomaly had spread through the sale of affected semen. The 78 identified carriers (table 1) do not represent an incidence as it is difficult to identify a particular bull's calves under extensive commercial farm management. The 
inability to positively identify calves would also account for the discrepancy between the expected number of carriers (113.5) and the observed number of 78 carrier cattle.

As the investigation had concentrated on only one Brahman line, it was deemed advisable to study the incidence of the anomaly in the general population. As shown in table 1, no translocation carrying animals were found in the sample studied. It is thus presumed that the abnormality, by virtue of its recent introduction to the country, is still restricted to the founder line.

Although widely distributed throughout the world, the effect of the translocation is still a point of conjecture. There are strong indications that the fertility of carrier animals is adversely affected (BLAZAK \& ELDRIDGE, 1977 ; GuSTAVSSON, 1979 ; KovaCS \& Csukly, 1980 ; Refsdal, 1976 ; SwarTZ \& Vogt, 1983). In Southern African Brahman cattle, the extensive farming conditions and the lack of reliable data under such conditions did not allow for meaningful statistical analysis of fertility. In the absence of evidence to the contrary, it is necessary to accept that the presence of the translocation causes a reduction in the fertility of carrier animals.

In a subsequent study, after the discovery of the $1 / 29$ translocation in the indigenous Nguni cattle (NeL et al., 1985), it was found that the growth rate of translocation carriers was $7-9$ index points higher $(P<0.05)$ than that of normal cattle (unpublished results). As an increased growth rate would be to the advantage of the beef industry, it was decided to investigate the possible effect of this anomaly in Brahman cattle. The results in table 2 show no significant difference in the growth of carrier animals compared with their normal half-sibs. Although not statistically supported by the present data there is a tendency towards increased growth in the translocation half-sibs. It would be worthwhile repeating this investigation using an increased number of calves born in different herds, seasons and environments.

Received April 30, 1987.

Accepted October 20, 1987.

\section{Acknowledgements}

We thank the Brahman Cattle Breeder's Society of South Africa for their support. We would also like to thank Taurus Co-operative, Dr. P.E. Lombard and Mr M.M. Scholtz for their contributions.

\section{References}

BlazaK W.F., Eldridge F.E., 1977. A Robertsonian translocation and its effect upon fertility in Brown Swiss cattle. J. Dairy Sci., 60, 1133-1142.

Di Berardino D., Iannuzzi I., 1982. Detailed description of R-banded bovine chromosomes. $J$. Hered., 73, 434-438.

Gustavsson I., 1969. Cytogenetics, distribution and phenotypic effect of a translocation in Swedish cattle. Hereditas, 63, 68-169.

Gustavsson I., 1979. Distribution and effects of the $1 / 29$ Robertsonian translocation in cattle. $J$. Dairy Sci., 62, 825-835. 
Kovacs A., Csukly S., 1980. Effect of the $1 / 29$ translocation upon fertility in Hungarian Simmental cattle. Proc. 4th Europ. Colloq. Cytogenet. Domest. Anim., Uppsala, June 10-13, 1980, 35-43, Swedish University of Agricultural Sciences, Uppsala.

Moorhead P.S., Nowell P.C., Mellman W.J., Battips D.N., Hungerford D.A., 1960. Chromosome preparations of leucocytes cultured from human peripheral blood. Exp. Cell Res., 20, 613-615.

Nel N.D., Harris E.J., Weiermans J.E., Meyer E.H.H., 1985. A $1 / 29$ chromosome translocation in Southern African Nguni cattle. The identification, occurrence and origin of the translocation. Génét. Sél. Evol., 17, 293-302.

Popescu C.P., 1977. Les anomalies chromosomiques des bovins (Bos taurus L.). Etat actuel des connaissances. Ann. Génét. Sél. Anim., 9, 463-470.

Popescu C.P., Ronne M., Cribiu E.P., Boscher J., 1982. The standardization of the R-banded karyotype in cattle (Bos taurus L.). Proc. 6th Europ. Colloq. Cytogenet. Domest. Anim., Milano-Gargnano, June 7-11, 1982, 172-190, Edizione curata da CLESAV, Milano.

RefSDAl A.O., 1976. Low fertility in daughters of bulls with $1 / 29$ translocations. Acta. Vet. Scand., 17, 190-195.

Swartz H.A., VoGt D.W., 1983. Chromosome abnormalities as a cause of reproductive inefficiency in heifers. J. Hered., 74, 320-324. 